\title{
ENSINO MÉDIO: EMPRESÁRIOS DÃO AS CARTAS NA ESCOLA PÚBLICA*
}

\author{
NORA KRAWCZYK ${ }^{* *}$
}

\begin{abstract}
Seria uma atitude muito ingênua esperar que as classes dominantes desenvolvessem uma forma de educação que permitisse às classes dominadas perceber as injustiças sociais de forma crítica [...].
\end{abstract}

(Paulo Freire)

\begin{abstract}
RESUMO: A escola média brasileira está num momento de transição. Mas transição para onde? Este artigo ajuda a encontrar respostas para essa pergunta, analisando as mudanças no ensino médio e as influências que sofre o complexo e controvertido processo de definição de políticas. O texto examina o que se pode classificar como início de um processo de renovação da racionalidade pedagógica e organizacional desse nível de ensino, no qual têm surgido variadas modalidades, formas de organização e de trabalho pedagógico. Revela o papel privilegiado que uma fração do empresariado assumiu nessa renovação. Identifica as propostas curriculares e organizacionais que tendem à padronização nacional do ensino médio, ao mesmo tempo em que há uma forte fragmentação no interior das redes estaduais e de sua gestão político-educacional.
\end{abstract}

Palavras-chave: Ensino médio. Modelo empresarial de educação. Política educacional. Ensino médio integral. Reconfiguração do espaço público. Empreendedorismo.

\section{High SCHOOL: ENTREPRENEURS DEFINE THE RULES IN PUBLIC SCHOOLS}

ABSTRACT: Brazilian high schools are in a time of transition. But a transition to where? This article helps find answers to this question by analyzing the changes in high school education and the various influences that shape the complex and controversial process of defining policies. It examines what

Este texto contém resultados parciais da pesquisa em andamento intitulada "Ensino médio: um campo de disputa a ser explorado", financiada pelo CNPq através da Bolsa Produtividade.

** Faculdade de Educação da Universidade Estadual de Campinas (Unicamp). Campinas (SP) - Brasil.

Contato com a autora: <norak@uol.com.br> 
can be classified as the beginning of a renewal process in the pedagogical and organizational rationality at this level of education, which has given rise to various modalities and forms of organizational and pedagogical work. The analysis also reveals the privileged role that a part of the business sector assumes in this renewal process. It identifies the curriculum and educational proposals that tend to standardize high school education at a national level even while there is a strong fragmentation within state networks and their political-educational management.

Key words: High school education. Business model of education. Educational policies. Integral high school education. Reconfiguration of public space. Entrepreneurship.

\section{ÉNSEIGNEMENT SECONDAIRE: LES ENTREPRENEURS DÉFINISSENT LES RÈGLES DANS L'ENSEIGNEMENT PUBLIC}

RÉSUMÉ: Au Brésil, l'enseignement secondaire passe par un moment de transition. Mais une transition vers où ? Vers quelle direction? Cet article vous aidera à trouver des réponses pour cette question, en analysant les changements dans l'enseignement secondaire et les influences subies par le processus complexe et controversé de la définition de politiques. Le texte examine ce qui se peut classer comme le début d'un processus de renouvellement de la rationalité pédagogique et organisationnelle de ce niveau d'enseignement, au sein duquel on constate des modalités variées, ainsi que des formes d'organisation et de travail pédagogique. Il révèle le papier privilégié que certains chefs d'entreprise ont assumé dans ce renouvellement. Il identifie les propositions curriculaires et organisationnelles qui ont une tendence à la standardisation nationale de l'enseignement secondaire, tout en soulignant une forte fragmentation au sein des réseaux du système d'enseignement de différents Etats brésiliens et de leur gestion politique et éducative.

Mots-clés: Enseignement secondaire. Modèle d'éducation issu de l'entreprise. Formulation de la politique éducative. École secondaire intégrale.

\section{Introdução}

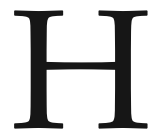

oje, com bastante frequência, a mídia afirma que o ensino médio brasileiro está em crise ou, em um tom mais alarmante ainda, fala do "apagão" do ensino médio. Ao mesmo tempo, constata-se uma hiperatividade no âmbito legal que resultou, nos últimos vinte anos, num conjunto de leis, resoluções, decretos, emendas, uns substituindo outros, sobrepondo o tempo político ao tempo necessário para efetivamente realizar mudanças na educação.

A prioridade dos tempos políticos e a invasão de informações negativas sobre o desempenho das escolas públicas criam condições - como em outros momentos ${ }^{1}$ - para soluções rápidas e até mágicas, tanto para a escola quanto para o futuro dos jovens. E preparam a sociedade para tais soluções. 
Talvez seja mais claro afirmar que o ensino médio vem apresentando complexidade crescente (novos desafios próprios de sua expansão e das mudanças culturais que estamos vivenciando), com importantes mudanças qualitativas e quantitativas que articulam tanto dificuldades quanto avanços nas estratégias e nas ações nesse nível de ensino. Podemos dizer que a escola média brasileira está num momento de transição. Mas, transição para onde?

Para compreender o que está acontecendo, a primeira fonte de análise refere-se aos dados estatísticos, que mostram como vem se dando o processo de expansão do ensino médio. Em 2004, o Brasil registrou o maior aumento de alunos matriculados, chegando a 9,17 milhões (crescimento de 34,5\% em dez anos), ainda que sem provocar uma ruptura importante nas desigualdades regionais, de raça e de sexo. ${ }^{2}$ Nos anos seguintes, nota-se uma tendência ao declínio da expansão do ensino médio, com pequena retomada a partir de 2008, tendo-se chegado a 2011 com 8,4 milhões de alunos matriculados. ${ }^{3}$ Provavelmente, esta retomada do crescimento tem a ver com a implantação do Fundo de Manutenção e Desenvolvimento da Educação Básica e de Valorização dos Profissionais da Educação (Fundeb), que veio estimular o crescimento da oferta de vagas, uma vez que estariam disponíveis recursos financeiros específicos. ${ }^{4}$ É verdade que houve nova queda no número de estudantes matriculados no ensino médio em $2012,{ }^{5}$ mas é preciso aguardar os dados dos anos seguintes para se verificar o que isso significa.

Já do ponto de vista de fixar os alunos na escola, de forma a que concluam seus estudos no período esperado, as estratégias e as ações dos poderes públicos não têm sido suficientemente exitosas. Em 2012, do total de estudantes matriculados no ensino médio no país, $31,1 \%$ tinham idade acima do esperado para a série que cursavam (AGÊNCIA BRASIL, 2013). Tal como o sobe e desce das matrículas, também a manutenção de alta porcentagem de distorção idade/série e os altos índices de abandono e fracasso escolar ainda não foram suficientemente estudados e compreendidos.

Tornar obrigatória a educação básica, ${ }^{6}$ assegurando-se sua oferta gratuita para todos os que a ela não tiveram acesso na idade própria (BRASIL, 2009), ${ }^{7}$ conferindo à educação média o estatuto de direito de todo cidadão, foi uma decisão importante. Contudo, não é uma tarefa fácil definir políticas para esse nível de ensino, em razão da falta de consenso sobre sua função social: é preciso criar condições institucionais e de aprendizagem em sintonia com o mundo contemporâneo para toda a população e, principalmente, faz-se necessária uma cultura social democrática que tenha como princípio de qualidade a inclusão de todos os nossos jovens, numa relação significativa com a escola.

Ninguém poderia negar que a educação brasileira deixa muito a desejar. Tampouco se pode desconhecer que as deficiências atuais do ensino médio no Brasil 
são, entre outros sinais, expressões da presença tardia, no país, de um projeto de democratização da educação pública, que até o presente está inacabado e ainda sofre os abalos das mudanças que, a partir da segunda metade do século $X X$, transformaram significativamente a ordem social, econômica e cultural, com importantes consequências para toda a educação pública (FERNANDES, 1981).

Paralelamente, nas últimas décadas, amplos setores da chamada “opinião pública" abandonaram o ideário da igualdade de acesso ao conhecimento que permita ao estudante desenvolver-se plenamente como cidadão. Portanto, eliminaram essa dimensão democrática de suas avaliações sobre a eficácia do sistema educacional, sem a qual o que resta é a ênfase no sentimento negativo diante da educação escolar brasileira, acentuando-se sempre sua "baixa qualidade".

Ora, quando duas pessoas falam de qualidade na educação, nem sempre estão dizendo a mesma coisa. A noção de qualidade é um conceito histórico e socialmente construído e sujeito a constantes negociações. Por isso, se entendermos a crise como um momento que define uma situação de tensão, disputa e conflito, podemos afirmar que sim, sem dúvida, o ensino médio brasileiro está em crise, e o mesmo ocorre com o que se entende por qualidade na educação.

O que tem sido proposto para resolver esta crise? Em que direção está indo o ensino médio brasileiro? Como em quaisquer momentos de transição, projetos educacionais diferentes e até opostos colocam-se em disputa. Nessa disputa, que setor da sociedade tem dado as cartas?

A segunda fonte de análise para se compreender o que acontece no ensino médio é acompanhar o que têm feito as secretarias estaduais de Educação, órgãos que, efetivamente, operam esse nível de ensino. Nelas, o que se observa é que um setor do empresariado assumiu lugar privilegiado na definição de políticas educativas. Naturalmente, isso não impede a presença de tensões e conflitos, contradições nas políticas implementadas e, principalmente, na sua concretização no âmbito escolar.

A atitude proativa desse setor está presente em diferentes espaços de ação pública - executivos federais e estadual, legislativo, municípios - e, sobretudo, conta com o apoio do aparato de Estado que compartilha suas propostas e procura implantá-las.

São propostas que procuram aplicar modelos de gestão empresarial ao âmbito educativo. Nesse contexto, as evidências e o pragmatismo tornaram-se, nos últimos trinta anos, as palavras de ordem na definição de políticas e o registro de experiências bem-sucedidas e resultados mensuráveis tornaram-se os conhecimentos privilegiados (KRAWCZYK, 2014).

Tal lógica promove a circulação de um conjunto de propostas que, muitas vezes, influenciam as ações políticas; quando não, servem para legitimar decisões já tomadas. Abre espaço também para que institutos e fundações empresariais, em 
associação com ONGs e empresas de consultoria, passem a buscar evidências empíricas nacionais e internacionais e implementar projetos pilotos, formando-se, assim, uma espécie de "banco de ideias e de experiências" viáveis para reprodução em larga escala, passíveis de se tornarem políticas públicas.

Essas ideias e experiências têm como objetivo a melhoria das avaliações institucionais. São voltadas, principalmente, para a implantação de novas "tecnologias" na gestão dos órgãos públicos e/ou nas unidades escolares e para a mudança das condições do trabalho docente, e aplicáveis para qualquer nível de ensino (DELVAUX, 2009; BARROSO; NATÈRCIO, 2011).

\section{As inovações em curso no Brasil}

Nos últimos dez anos, o ensino médio brasileiro não só tem sido afetado por um enorme conjunto de resoluções, decretos, leis, mas também vem sofrendo influência de múltiplos atores, num processo complexo e controvertido de definição de políticas e estratégias para melhorar os índices de rendimento das escolas. Há o governo federal, com programas propondo nova abordagem pedagógica e organizacional. Há as secretarias estaduais de Educação, que arcam com o peso maior da oferta de matrículas, com a responsabilidade de responder às demandas e de concretizar ideias, estratégias e ações. E há também os atores privados, ligados ao mundo empresarial (fundações, institutos, ONGs, empresas de consultoria), que não apenas oferecem ajuda material à escola pública, mas atuam também no auxílio à gestão e, até mesmo, influenciam fortemente nas propostas curriculares.

Na pesquisa em fase de finalização, intitulada: "Ensino médio: um campo de disputa a ser explorado", ${ }^{8}$ foi possível observar o início da renovação de sua racionalidade pedagógica e organizacional, que progressivamente vai criando uma variedade de modalidades, de formas de organização e de ensino - diferente do tradicionalmente oferecido.

A expansão do ensino médio é bastante diferenciada no conjunto do país, assim como o estágio das mudanças na sua oferta. Entretanto, é possível identificar propostas curriculares e organizacionais hegemônicas, que tendem à padronização nacional desse nível de ensino. Ao mesmo tempo (e, talvez, contraditoriamente), há uma forte fragmentação no interior das redes estaduais do ensino médio e de sua gestão político-educacional.

Em nome da flexibilização da oferta educacional e da eficiência do sistema educacional, coexistem a "velha" escola média e novas modalidades de ensino, com diferentes formatos (inclusive no interior de cada modalidade). Nas secretarias de Educação, cada modalidade tem sua coordenação e sua equipe, mas as diferentes modalidades não se conversam. 
As principais políticas estaduais convergem para a construção do ensino médio com uma jornada escolar ampliada (paralela ao matutino, vespertino e noturno) e para a expansão da oferta de educação profissional por meio do ensino médio integrado; propostas encorajadas pelo governo federal. Atualmente, existem no Brasil as seguintes modalidades e formatos:

- Ensino médio "regular", de tempo parcial (diurno e noturno).

- Ensino médio integrado à educação técnico-profissional.

- Ensino médio concomitante com a educação técnico-profissional.

- Ensino médio integral (ou jornada completa).

- Ensino médio semi-integral (dois dias com jornada completa).

- Ensino médio integral com gestão compartilhada.

\section{Ensino médio regular}

Mantém-se com suas quatro ou cinco horas-aula por dia, tendo sofrido poucas alterações. Não têm sido priorizadas políticas públicas para essa modalidade, ainda que represente a maioria das instituições públicas de ensino médio. Recentemente, em muitos estados, essas escolas começaram a aderir ao Programa Ensino Médio Inovador (Proemi), depois que foram introduzidas mudanças neste Programa que flexibilizam as exigências com relação à jornada escolar diária e ao número de professores com jornada completa na escola. ${ }^{9}$ É o caso, por exemplo, de Pernambuco, São Paulo, Paraná, Ceará, entre outros, onde as secretárias de Educação têm incentivado a adesão ao Proemi. Em contrapartida, vários projetos de instituições empresariais (através de suas fundações e/ou institutos) estão sendo implementados, ainda que num número limitado de unidades escolares, e não exclusivamente no ensino médio regular.

No caso do ensino médio regular noturno, há certo abandono por parte da política pública e uma forte tendência a substituí-lo por diferentes programas de educação de jovens e adultos (EJA), oferecidos à noite. São vários os argumentos que questionam a manutenção do ensino regular noturno. Um deles é a diminuição da demanda, outro é que ele existe pelas altas taxas de reprovação no diurno, o que acaba "empurrando" o estudante para o ensino noturno. E um terceiro argumento é que o ensino noturno estaria funcionando como uma "reserva de mercado" para o professor, que nele pode complementar seu salário (SOUZA, 2013).

De fato, tem diminuído o número de jovens de 15 a 17 anos que estudam e trabalham ou procuram trabalho. Em 2001, o total era de 31,7\% dos jovens dessa 
faixa etária, caindo para 25\% em 2011 (PNUD, IBGE). De qualquer forma, são números significativos demais para serem desprezados.

Além disso, as motivações dos estudantes para a escolha do ensino noturno merecem maior atenção, porque expressam uma realidade social bastante complexa, que inclui, entre outros aspectos, a necessidade de mudanças profundas em todo o ensino médio. Quando se analisam essas motivações, chama atenção o desajustamento ou descompasso entre a percepção adulta do "ambiente juvenil" em relação à percepção dos jovens (SPOSITO, 2005). Por isso, muitas vezes, o clima escolar do noturno, "mais adulto", é mais atraente para os jovens. Ao mesmo tempo, permite-lhes trabalhar no mercado informal, para serem mais independentes ou para se sentirem úteis à sua família, motivação muito reforçada pela crescente importância que adquire o consumo nas relações sociais. Podem, ainda, ser contratados como estagiários, experiência significativa porque funciona como um diferencial entre seus pares, na hierarquização dos currículos dos jovens trabalhadores.

A Comissão Especial para a reformulação do ensino médio constituída pela Câmara dos Deputados em maio de 2012, cujo relatório final resultou na criação do PL n. 6.840/2013, tem entre suas propostas considerar o ensino noturno como uma "exceção", direcionada para os alunos maiores de 18 anos que trabalham (RELATÓRIO FINAL, dez. 2013)..$^{10}$ Assim, a Comissão desconhece a alta porcentagem de alunos de 15 a 17 anos que trabalham e que correm o risco de serem excluídos do sistema de ensino. Desconhece também que já existe a modalidade EJA de ensino médio para a faixa a partir de 18 anos.

Em outras palavras, a Comissão da Câmara Federal desconhece o grau de iniquidade da sociedade brasileira, exacerbada pela indução ao consumo cada vez mais agressiva por parte dos meios de comunicação. Nesse complexo cenário, cabe à educação provocar uma real transformação - e não pequenas adaptações - da instituição escolar, que permita recuperar seu papel cultural e formar jovens críticos e não reféns da "sociedade do consumo" na qual lhes cabe viver.

Por último, o argumento da complementação do salário docente não faz mais do que reafirmar as más condições de trabalho e a baixa qualidade de vida dos professores.

\section{Ensino médio integrado à educação profissional técnica de nível médio}

Em 2004, o MEC apresentou a proposta de um ensino médio integrado à educação profissional técnica de nível médio ${ }^{11}$ como uma alternativa de ruptura com a histórica dualidade entre formação propedêutica e profissionalizante, que parecia ter-se aprofundado nos anos anteriores. Essa proposta retomou o princípio da 
politecnia e pretendia superar a dicotomia com a educação profissional, mediante a integração de seus objetivos e métodos, contemplando, num único currículo, os conteúdos da educação geral e da formação profissional, configurando o trabalho como princípio educativo (LODI; KRAWCZYK, 2008).

Hoje, o ensino médio integrado à educação profissional técnica de nível médio convive, em muitos estados, como em São Paulo, por exemplo, com a modalidade concomitante. Nesta última, a educação profissional fica sob a responsabilidade do sistema privado, com financiamento público.

As diferenças entre ambas as modalidades são bastante significativas. $\mathrm{O}$ ensino médio integrado procura estabelecer um vínculo entre o aprendizado profissional e o acadêmico. Trata-se de um curso único, com a integração e a interdependência de todos os componentes curriculares - quer os mais voltados para a formação geral, quer os relativos à base tecnológica de determinada habilitação profissional -, oferecidos simultaneamente, desde o início até a conclusão do curso. Não é possível concluir o ensino médio sem a conclusão do ensino técnico de nível médio e vice-versa.

Sem dúvida, um projeto dessa natureza implica, para sua concretização, assumir investimentos em infraestrutura, proposições curriculares realmente integradoras entre formação geral e tecnológica e políticas de valorização dos profissionais da educação, entre outras frentes que ainda não se vislumbram com clareza. Por sua vez, esta modalidade tem assumido diferentes formatos, dependendo principalmente do grau de desenvolvimento do ensino técnico de nível médio em cada um dos estados e da articulação entre ambas as redes.

Em alguns casos, como Pernambuco, a articulação entre ambas as redes (regular e técnico de nível médio) não é tão difícil, já que elas estão sob a direção da Secretaria de Educação Estadual. No caso de São Paulo, é um pouco diferente.

A Secretaria da Educação de São Paulo (SEE) tem parceria com os Centros Estaduais de Educação Tecnológica (Cetecs) e com os Institutos Federais de Educação, Ciência e Tecnologia (Ifets). ${ }^{12}$ Com os Cetecs, que estão sob a responsabilidade da Secretaria de Ciência e Técnica, a SEE tem pouca autonomia de decisão-; enquanto, com os Ifets a parceria é bem menos conflitiva.

O governo federal tem como política a expansão dos Ifets no marco do Programa Brasil Profissionalizado, mas essa expansão tem sido tímida, quando comparada à demanda. Por isso, não é possível dizer que o ensino médio integrado em São Paulo tenha um formato único. Em ambos os casos, ele está fortemente condicionado às características dos Ifets e dos Cetecs: condicionado às vagas oferecidas em cada unidade escolar desses Centros; condicionado à organização e integração dos cursos; condicionado aos processos de seleção do Ifet e do Cetec, que são diferentes. 
Por exemplo, no Cetec, o aluno do ensino médio que pretende cursar a modalidade integrada precisa realizar uma prova de ingresso, enquanto o acesso ao Ifet ocorre por sorteio.

É interessante destacar o deslocamento das preocupações do setor empresarial brasileiro com relação à educação formal. Hoje, o foco desse setor está não só no ensino técnico, como ocorria em outras épocas, mas também, e principalmente, na reorganização curricular do ensino médio regular, com a ampliação do tempo diário de permanência do aluno na escola e mudanças curriculares e na sua gestão. Esse movimento nas demandas do setor empresarial pode ser explicado pelo fato de grandes empresas, inclusive no setor agropecuário, estarem criando as chamadas "universidades corporativas" para prover competências e conhecimentos específicos em cada área. Há também o interesse em preservar o Sistema S. Outro ponto não menos importante é a preocupação do empresariado em reafirmar a responsabilidade do Estado de assegurar a formação geral básica do aluno: conhecimentos essenciais em matemática, português, língua estrangeira e as competências necessárias para ser exitoso no mundo do trabalho. ${ }^{13}$

\section{Ensino médio integral}

Uma primeira leitura da dinâmica do governo federal e dos governos estaduais nos leva a pensar que o Programa Ensino Médio Inovador (Proemi), do Ministério de Educação, é o arcabouço das inovações de escola de jornada completa nos estados e, portanto, atua como mecanismo indutor. Porém, como veremos na continuação, a dinâmica é um pouco diferente e outros atores, principalmente privados, exercem forte pressão para implantação da jornada completa no ensino médio.

A implantação do modelo de ensino médio de jornada completa (com sete ou nove horas diárias), ainda que num número relativamente pequeno de escolas, na maioria dos estados é a modalidade que recebe mais atenção por parte das secretarias de Educação, crescendo ano a ano ${ }^{14}$ e criando em alguns estados um conjunto de unidades escolares diferenciadas. Vamos nos deter na análise desse fenômeno

São Paulo está implantando o novo modelo de escola média de tempo integral desde 2011 (16 unidades em 2012, 53 em 2013). As unidades escolares passam por reforma física, mudanças nos recursos humanos e implantação de um projeto de gestão e pedagógico. A expansão desse modelo é limitada, porque pretende ser uma das opções curriculares oferecidas ao estudante. Já no caso de Pernambuco, iniciou-se em 2008 um processo intensivo de expansão do ensino médio de período integral, ${ }^{15}$ no marco de uma política universalista, nem sempre acompanhada de reforma física das escolas nem de reformulação curricular, mas sempre partindo de reformulações na gestão das escolas e nas condições de trabalho docente. 
Encontramos também o ensino médio semi-integral e o ensino médio integral com gestão compartilhada. No primeiro caso, a ampliação da carga horária é menor, com dois dias de jornada completa, possibilitando assim que se mantenham os dois períodos diurnos (manhã e tarde), o que contorna o problema da falta de espaço físico.

Já o ensino médio integral com gestão compartilhada é resultado de iniciativas de instituições e/ou fundações privadas que elaboram propostas pedagógicas para ser aplicadas em uma ou duas escolas de ensino médio e oferecem a infraestrutura e os recursos humanos (técnicos) e materiais. São geridas conjuntamente por um profissional da rede pública e um membro da instituição parceira. São projetos isolados como, por exemplo, os implementados pelo Instituto Oi e pela Fundação Pão de Açúcar em alguns estados. Essas escolas possuem infraestrutura e projeto pedagógico diferenciados e, devido à grande demanda, têm provas de ingresso para selecionar seus alunos.

As escolas com jornada ampliada são cada vez mais requeridas por diferentes setores da sociedade, que enxergam no maior tempo escolar a salvação do ensino e da juventude. A necessidade de ampliação é justificada em alguns casos com argumentos assistencialistas, porque permite que os jovens estejam "fora das ruas e das drogas" e em outros com argumentos "pedagógicos" de diferentes índoles. Para alguns, o aspecto profissionalizante é o decisivo. Outros associam mais tempo na escola a melhor rendimento. E há os que visualizam a escola integral como a possibilidade de vivenciar experiências que possibilitem uma formação humana plena, articulando ciências, tecnologia, cultura e trabalho numa proposta político-pedagógica.

A extensão da jornada escolar é um tema que está sendo discutido em diferentes países com alguns pressupostos comuns que não foram suficientemente estudados e muitos deles respondem a percepções equivocadas. Por exemplo, a maioria dos países europeus não têm jornada completa, principalmente aqueles que costumam ser citados como referência de "boa escola", como é o caso, entre outros, de Finlândia, Dinamarca, França e Bélgica.

Não existe associação necessariamente positiva entre o tipo de jornada escolar e o rendimento dos estudantes. Uma política que muda o "tempo escolar" envolve outros tempos tais como o tempo da família, o tempo na organização do trabalho material, o tempo interno do adolescente, o tempo na vida social e laboral do jovem, entre outros tempos dos quais o estudante compartilha. Deveríamos fazer várias perguntas antes de tomar a decisão de uma política deste porte, evitando entulhar o sistema educacional com inovações.

O que seria mais adequado para a realidade brasileira: a universalização da jornada completa no ensino médio ou a oferta de formatos escolares diferentes? Que consequências sociais e educacionais poderiam trazer uma ou outra opção? 
Fala-se de extensão da jornada a partir de sete horas e já temos estados onde os alunos ficam 9,5 horas na escola. Duas horas a mais ou duas horas a menos não afeta a vida do estudante? O horário escolar é compatível com o relógio interno da adolescência? Que significa para um adolescente ficar numa instituição por tantas horas? Será que sua possibilidade de aprendizagem melhora? Que projeto pedagógico poderia otimizar esse tempo escolar? Existem projetos divergentes por trás das demandas por implementação da jornada completa? Estas e outras tantas perguntas estão ausentes no debate educativo. De forma aligeirada, pretende-se implementar uma política que muda a lógica do tempo e do espaço, que são os alicerces da organização escolar tal como a conhecemos. Sem dúvida, o formato atual da escola média não dá conta de uma revisão profunda dos processos de aprendizagem, mas será que desta maneira vamos ter uma educação escolar melhor?

Como afirma Harvey (2012, p. 187): “O espaço e o tempo são categorias básicas da existência humana. E, no entanto, raramente discutimos seu sentido; tendemos a tê-los por certos e lhes damos atribuições do senso comum ou autoevidentes".

O Programa de Desenvolvimento dos Centros de Ensino Experimental (Procentro) inspirou a implantação da jornada completa hoje com maior presença nos estados brasileiros (Sergipe, São Paulo, Ceará, Piauí e Rio de Janeiro, entre outros). Surgiu em Pernambuco em 2002 e se transformou numa "experiência exitosa”, um modelo e, portanto, um conhecimento válido para a ação política. Esse Programa nasceu da iniciativa de um empresário ${ }^{16}$ que, depois de implementar um projeto piloto em 11 escolas públicas com gestão compartilhada público-privada, fundou, com o apoio de outros empresários, o Instituto de Corresponsabilidade Educacional (ICE) para difundir o modelo de gestão escolar Tecnologia Empresarial Sócio-Educacional (Tese) (MAGALHÃES, 2008; DIAS; GUEDES, 2010).

A Tese, ${ }^{17}$ como seu nome indica, é a adoção de um conjunto de técnicas e instrumentos (planos, compromissos, metas, resultados, avaliações, incentivos e responsabilização) trazidos do mundo empresarial, sistematizados e transformados em conhecimentos passíveis de serem aplicados à educação e replicáveis em diferentes contextos, para tornar mais eficientes a organização e a gestão do sistema educacional e de suas instituições e garantir um regime de carreira de magistério "mais atrativo". Entenda-se aqui por eficiência a capacidade de obter melhor relação entre rendimento e dispêndio.

O ICE atua na implantação e no acompanhamento da Tese em escolas médias de jornada completa, com as equipes de várias secretarias de Educação. Prevê um processo seletivo (com várias etapas) dos professores entre os componentes do corpo docente permanente. Os aprovados assumem cargos comissionados na escola 
integral, mantendo seu cargo efetivo numa outra escola, o que permite a sua remoção, a qualquer momento, da escola integral. São capacitados e periodicamente avaliados em diferentes dimensões: adequação ao modelo de gestão e pedagógico, atuação na função que exercem, comportamento no ambiente de trabalho, comprometimento com o trabalho em equipe e aprimoramento profissional. Recebem uma gratificação, por desempenho, de aproximadamente $75 \%$ do salário ${ }^{18}$ e, se não cumprem com as expectativas previstas pelo Programa, são removidos e voltam à escola onde mantêm seu cargo. Existe um contrato explícito e outro implícito. Os docentes sabem que são avaliados, conhecem os critérios de avaliação e que disso dependem a sua permanência na escola e a gratificação. Contudo, também existe uma espécie de pacto entre o poder público e os docentes para não pôr em questão o modelo.

A proposta pedagógica busca desenvolver uma cultura empresarial nos jovens estudantes, dotando-os de maior capacidade de resistência e adaptação a situações novas. Seu esforço e o desenvolvimento dessas capacidades permitem-lhes permanecer com êxito na escola. Isso se materializa tanto nos objetivos da proposta pedagógica, quanto na transposição progressiva da linguagem do mundo empresarial para a escola, identificando-a com a vida na empresa e o jovem, com o trabalhador/empreendedor.

Trata-se de fazer com que o jovem aprenda a projetar seu futuro e a elaborar um plano de ação para seu desenvolvimento acadêmico durante a passagem pela escola e, posteriormente, para seu desenvolvimento profissional; envolve a capacitação no exercício da autonomia, da iniciativa e do compromisso por parte do jovem; uma cultura da trabalhabilidade e de empreendedorismo que lhe permita inserir-se e atuar no "novo" mundo do trabalho e desenvolver a capacidade de autogestão. O protagonismo juvenil é outro princípio da proposta pedagógica, envolvendo o jovem nos projetos sociais e educativos da escola, criando diversas formas de autogestão entre eles, com finalidades sociais, esportivas, ambientais, entre outras.

O modelo tem particularidades na execução em cada um dos estados que merecem estudos específicos, mas cabe ressaltar que os princípios enunciados na gestão da escola e o modelo pedagógico são estruturantes da proposta (LIMA, 2011; GOVERNO DO ESTADO DE SÃO PAULO, 2011). Todavia, as escolas traduzem a proposta pedagógica segundo suas possibilidades e convicções e, por isso, há opções bastante distintas no aproveitamento do tempo integral das escolas: organização da grade curricular com duas aulas geminadas da mesma disciplina; aumento da carga horária de Língua Portuguesa e Matemática; atividades onde se põem em prática os conceitos aprendidos nas disciplinas; cursos eletivos dentro e fora do horário escolar - línguas, robótica, informática, empreendedorismo, entre outros -, oferecidos pela própria escola e/ou por empresas. Alguns deles oferecem poucas vagas e os alunos interessados são selecionados segundo seu desempenho escolar. 
Não é possível identificar programas e/ou ações articuladas que possam caracterizar uma política para o ensino médio. Pelo contrário, em muitos casos, são imensas quantidades de pequenas ações, de parcerias, consultorias e convênios - como nos disse um entrevistado, responsável pelos convênios da sua secretaria: "são tantos que não consigo acompanhar".

Uma expressão disso é a fragmentação da ação política das secretarias de Educação: são equipes, responsáveis pela execução de programas, que não conversam entre si.

No entanto, é possível, sim, perceber uma tendência de mudança hoje hegemônica no cenário educacional brasileiro. Essa tendência tem como pressuposto a dificuldade da escola para dar respostas às demandas, às necessidades e às condições de aprendizagem dos novos contingentes de jovens que estão ascendendo a esse nível de ensino. Mas, principalmente, tem como pressuposto a necessidade de "modernizar a gestão pública". As experiências exitosas de algumas gestões empresariais se apresentam como um conhecimento válido para promover maior produtividade das instituições públicas. No entanto, é necessária certa adaptabilidade, principalmente pelos constrangimentos que ainda colocam as leis trabalhistas, as carreiras docentes, as próprias dinâmicas das secretarias de Educação e as condições socioculturais dos alunos.

O modelo (ou tecnologia) de gestão hoje valorizado pela sua eficiência e a proposta pedagógica que o acompanha articulam um conjunto de atributos individuais a outros atributos próprios das relações de mercado: valores e comportamentos adequados à reprodução do estágio atual do capitalismo. Deles deriva um conceito de qualidade educacional próprio da cultura empresarial, que se ancora na competitividade, na eficiência, no individualismo, na liderança, no controle dos resultados e no retorno em curto prazo. Nas escolas que adotam esse conceito há uma simulação, por meio do modelo pedagógico, das estratégias e das competências necessárias para um empreendimento profissional e/ou empresarial, dependendo do "sonho de cada aluno". É a construção de um futuro ancorado na ideia do esforço individual, num mundo "dado como dado", no qual não entra a compreensão crítica capaz de transformá-lo.

Essa ideologia é reforçada sistematicamente pela mídia e por diferentes discursos públicos, que associam o crescimento da economia às mudanças no rendimento escolar dos estudantes. Cada vez mais encontramos entre os economistas aqueles preocupados com a educação, tendo os indicadores educacionais como dimensão de análise da competitividade e do potencial de crescimento econômico. É como se indicadores como os resultados do Programa Internacional de Avaliação de Estudantes (Pisa) passassem a competir com os tradicionais índices de inflação e de evolução do Produto Interno Bruto para avaliar a perspectiva de desempenho dos países. 
A literatura internacional vem alertando sobre a necessidade de a escola mudar, para poder produzir uma interlocução crítica e reflexiva com o mundo contemporâneo (JACINTO; TERIGI, 2007; KRAWCZYK, 2009; TIRAMONTI, 2011), mas as políticas a que estamos assistindo, em nome da inovação e da reformulação do processo de aprendizagem, não resultam em mudanças que transformem a dinâmica escolar do país. Pelo contrário, as práticas anacrônicas de ensino-aprendizagem e de controle continuam sendo o mais comum nas escolas e a pressão por melhores resultados também não incentiva a experimentação de processos novos de aprendizagem, por receio de não atingir os resultados previstos. Dessa forma, ao contrário do que seria recomendado, reproduz-se o conhecido: o reforço escolar, quando não os processos de seleção ocultos.

Ao mesmo tempo, ao influir nos currículos e nas demais atividades escolares, os agentes privados colocam-se em condições de utilizar a escola como plataforma para atender a interesses privados dos mais diversos. São propostas que afetam profundamente as experiências escolares dos jovens estudantes e o trabalho docente. Processam formas distintas de seleção do alunado, de organização do tempo escolar e curricular, de acompanhamento e controle do ensino, de organização e remuneração do trabalho docente, no interior do sistema público de ensino médio. Recomendam: maior autonomia dos gestores (diretores) de escola para contratar e demitir professores, contratar serviços de apoio e organizar o orçamento, além de maior participação do setor privado na gestão educacional. Paralelamente, exigem prestação de contas e inspeções intensivas de controle de qualidade; recompensas e sanções baseadas no rendimento dos alunos; aumento de supervisão na sala de aula, com monitoramento e avaliações sistemáticas. A avaliação é a chave do êxito do modelo proposto, reconhecido como modelo gerencial da educação. Tem o poder de direcionar o trabalho docente, de diminuir o espaço do imprevisível e de impor uma normalização (ZIEGLER, 2012).

Encontramos, num mesmo estado, numa mesma cidade, escolas públicas com boa infraestrutura, docentes com gratificação extra, que convivem lado a lado com escolas sem nenhuma dessas características. Naturalmente, a população prefere matricular seus filhos nas primeiras, que terão condições de selecionar os melhores alunos e, só por esse fator, já apresentariam os melhores rendimentos. Ao mesmo tempo, diversas propostas para organizar a escola, o trabalho docente e a vida dos estudantes convergem numa nova forma de escola, centrada na melhoria da educação em algumas disciplinas e competências básicas, no conhecimento quantificável e mensurável e numa maior responsabilização, sobretudo dos docentes, pelos resultados. Enfim, temos, aparentemente, um leque de oferta de ensino médio diversificado, mas na realidade é uma oferta fragmentada que, ao mesmo tempo, padroniza uma "nova forma escolar". 
Quase finalizando o ano de 2013, foi aprovada, no âmbito das comissões na Câmara de Deputados, mais uma nova proposta de reformulação do ensino médio ${ }^{19}$ que deu origem, com já dissemos, ao PL n. 6.840 de 2013. Busca, entre outras medidas, retomar o dualismo organizacional com a implantação no terceiro ano de opções educacionais diferenciadas. ${ }^{20}$ Diversificam-se as trajetórias de formação: umas mais imediatistas e utilitaristas e outras de formação científica e de longo prazo, fragmentando ainda mais o processo formativo dos jovens e antecipando decisões ao serviço da reprodução social. A proposta justifica-se na importância de adequar o ensino às preferências e às necessidades dos estudantes. Justificativa claramente segregacionista, porque pressupõe que os jovens que optarem pelo mercado de trabalho ou precisarem inserir-se nele não continuarão estudos em nível universitário e, se decidirem por ele, terão um alto "preço a pagar", porque deverão voltar à escola e cursar um novo percurso formativo. Optar-se pela organização diversificada será um franco retrocesso em relação aos passos que já foram dados no sentido de eliminar a indesejável oposição entre ensino propedêutico e formação profissional, entre conhecimento geral e conhecimento específico.

Outra expressão da fragmentação da política de ensino médio é o fato de que essa proposta de reformulação, promovida pela Comissão da Câmara Federal, desconsidera as diferentes modalidades de ensino médio hoje presentes no país como parte de uma Política Educacional (com maiúscula) para esse nível de ensino, algumas inclusive legalmente constituídas em quase todo o território nacional. ${ }^{21}$ É o caso, por exemplo, do ensino médio integrado à educação profissional técnica de nível médio, que, como vimos, tem uma proposta pedagógica própria de formação técnica de nível médio, está em processo de implantação e ainda nem sequer foi possível avaliar.

O modelo pedagógico de ensino médio de tempo integral em expansão no país - que detalhamos anteriormente - e a proposta de reformulação do ensino médio da Câmara dos Deputados - apresentada somente três anos após a definição das Diretrizes Curriculares Nacionais para Ensino Médio - são exemplos bastante significativos. Corroboram que o currículo de ensino médio é, foi e será um campo de disputa e, nesse contexto, a relação entre educação e trabalho é um dos temas que gera mais controvérsias. Assim foi nas diferentes reformas educacionais durante $o$ século $X X$, assim tem sido neste século XXI.

Se observarmos o movimento histórico do desenvolvimento do ensino médio no Ocidente, perceberemos que, segundo as políticas adotadas, é possível promover a diferenciação educacional precoce e altamente seletiva ou, pelo contrário, retardá-la.

O cenário educacional atual mostra que estamos num processo progressivo de universalização do ensino médio e, ao mesmo tempo, regressivo na distribuição 
do conhecimento socialmente produzido. Não temos novas metodologias de ensino nem uma prática escolar que possibilite a interlocução crítica e reflexiva com o mundo contemporâneo. Mais ainda, podemos afirmar que o processo de expansão do ensino médio corre o risco de acontecer de maneira simultânea com a intensificação de processos que reforçam a desigualdade de oportunidades da sociedade brasileira.

\section{Conclusões}

Tudo isso se encontra ainda em processo de elaboração e/ou implantação, o que torna prematura qualquer análise dos resultados, tanto das iniciativas do governo federal e do uso que delas fazem os estados, quanto das iniciativas do setor privado. No entanto, começa a ficar evidente a presença de um novo estágio de reestruturação do espaço público e de suas instituições. Encontramos alterações importantes no modo como se elaboram e implementam políticas educacionais e uma nova lógica na racionalidade no âmbito político-educacional, que sugere novos modos de regulação e de dinâmicas diferentes para a configuração do ensino médio, esboçando um universo novo nesse nível de ensino no Brasil.

Na década de 1990, em pleno período de implantação do neoliberalismo na América Latina, assistimos à pressão "externa" e a mecanismos de convencimento, oriundos dos organismos internacionais e do Executivo nacional, para que o empresariado brasileiro - por meio das políticas sociais - passasse a assumir parte da responsabilidade pelo bem-estar da população. Surgiu, assim, o slogan "responsabilidade social", para nomear o processo de descentralização de responsabilidades e atribuições para o mercado, do qual o Programa de Comunidade Solidária funcionou como ponta de lança. Presidido pela primeira-dama Ruth Cardoso, nasceu com o propósito de otimizar as formas de gerenciamento de um conjunto de programas sociais por meio da participação da sociedade civil (especialmente o empresariado) no combate à pobreza. Começam, assim, a surgir regulamentações e figuras jurídicas da sociedade civil na prestação de serviços públicos, ${ }^{22}$ que, através de parcerias, complementaram o orçamento público com recursos privados.

Hoje o movimento é diferente. Não é mais necessário estimular o empresariado a se envolver nas questões sociais, como fez a Comunidade Solidária. Existe uma presença constante de movimentos empresariais, em diferentes instâncias de decisão político-educativa, que coletivamente e/ou individualmente se entrelaçam com os quadros políticos, no Executivo nacional, estadual e municipal e no legislativo, estabelecendo formas explícitas e implícitas de cogestão. ${ }^{23}$

Naturalmente, a escola pública é um nicho de mercado importante, recriado e estimulado constantemente pelo setor privado, que atua em áreas como material 
didático, formação de professores, consultorias, entre outras. No entanto, essa atuação não se resume apenas à realização de negócios com o governo, mas também (e cada vez mais) em implantar uma determinada ideologia nesse importante espaço de socialização das crianças e dos jovens (futuros trabalhadores), em inocular na escola pública a visão de mundo do empresariado.

É um novo estágio de reestruturação do espaço público, no qual o setor empresarial busca o fortalecimento da capacidade de execução do aparelho estatal e institucional, tomando as rédeas desse processo, em nome da necessidade do controle social.

O espaço público tornou-se altamente "concorrencial" e o setor da sociedade que hoje detém a hegemonia na arena político-educacional é o que Boito Jr. e Galvão (2012) chamam de burguesia interna, aquela "que ocupa uma posição intermediária entre a antiga burguesia nacional, passível de adotar práticas anti-imperialistas, e a velha burguesia compradora, mera extensão do imperialismo no interior desses países" (BOITO JR., 2012, p. 67). ${ }^{24}$ Muito heterogênea, englobando segmentos que vão de grandes grupos industriais ao sistema financeiro, passando pelas cadeias de varejo e outras áreas de negócio, a burguesia interna é, por si só, contraditória em seus interesses. O que unifica setores tão diferentes é que têm um compromisso com o capital financeiro internacional, mas também com uma indústria nacional preparada para a concorrência externa. Um dos principais elementos que a caracteriza é sua relação com o Estado brasileiro que, segundo Boito Jr., a protege e participa de seus projetos. Pode-se dizer também que, pelo menos no campo educacional, esse setor da burguesia tem um projeto para o país.

A competitividade do país no mercado globalizado é a chave desse projeto, e o lugar do Brasil no ranking internacional da "qualidade de seus recursos humanos" apresenta-se como uma das variáveis imprescindíveis para atingir esse objetivo. A qualidade da educação brasileira é convalidada por mecanismos de regulação internacionais, tais como o Pisa, que ao mesmo tempo direcionam o trabalho escolar. Nesse marco, certamente se requer da escola pública que seja ainda mais seletiva e institua mecanismos de seleção dos "bons" alunos que a escola estaria desperdiçando, ao dar excessiva atenção à maioria. Uma maioria que "fatalmente" vai fracassar. Se não for assim, o Brasil vai "perder seus melhores cérebros", como tantas vezes se ouve.

Essa pseudobusca da eficiência educativa representa o abandono da preocupação com a igualdade em pelo menos duas direções: a primeira é a que estabelece uma cisão entre a inclusão na escola e o direito do cidadão ao conhecimento socialmente construído. O que se quer de uma escola assim pensada, na qual a maioria dos alunos estará o dia todo na instituição, mas pouco vai aprender? Talvez ela seja 
apenas capaz de conter "crianças e adolescentes inquietos", afastando-os da rua e das drogas.

A outra direção de abandono da preocupação com a igualdade se dá ao sepultar o conceito de escola pública como espaço de integração e universalidade, que deveria ser valorizado e requerido por toda a sociedade. Ou seja, assume-se que ela é para os pobres, que está reservada para quem não pode pagar a escola particular. Ir por esse caminho significa derrubar a última possibilidade de confrontar o apartheid social brasileiro; significa renunciar a qualquer tentativa de construir uma sociedade menos injusta e desigual.

\section{Notas}

1. Nos Estados Unidos lançou-se, em 1981, a consigna "Uma nação em perigo", que deu nome ao relatório da National Commission for Excellence in Education e justificou as mudanças educacionais, supostamente em prol da melhoria da educação, durante a administração Reagan. Na década de 1990, o Banco Mundial também insistia na preeminência de mudanças nos sistemas educacionais latino-americanos para garantir o progresso da região e formulou recomendações no sentido de obter melhores resultados com o mínimo de investimento material e humano.

2. Por exemplo, na região Sudeste, os volumes de matrícula aumentaram anualmente de 1991 a 2000 (dobraram em dez anos), mas os de outras regiões aumentaram numa proporção maior, fazendo com que a participação do Sudeste na matrícula total do país caísse de $50 \%$ para $40 \%$ em vinte anos. Em São Paulo, que concentra um quinto das matrículas do país, houve uma tendência de queda de 2001 a 2007, aprofundando o fenômeno de toda a região Sudeste, mas houve novo crescimento a partir de 2008, período em que as matrículas de outras regiões diminuíram lentamente (fonte: MEC/Inep/Deed; inclui matrículas no ensino médio integrado à educação profissional e no ensino médio normal/magistério).-

3. Fonte: MEC/Inep/Deed; inclui matrículas no ensino médio integrado à educação profissional e no ensino médio normal/magistério.

4. Com a criação, em 2007, do Fundo de Manutenção e Desenvolvimento da Educação Básica e de Valorização dos Profissionais da Educação (Fundeb) -, amplia-se a vinculação de recursos para o ensino médio e da complementação financeira por parte da União.

5. Fonte: MEC/Inep/Deed.

6. Educação infantil, fundamental e média.

7. O regime de colaboração dos entes federados deve garantir a universalização do ensino obrigatório e estabeleceu-se o ano de 2016 como data limite para a implementação das políticas necessárias que assegurem a obrigatoriedade e a gratuidade do ensino básico (BRASIL, 2009). Amplia-se a vinculação de recursos para o ensino médio e da complementação financeira por parte da União - com a criação, em 2007, do Fundeb.

8. Bolsa Produtividade 2010-2013 (CNPq).

9. Para a adesão ao Programa, as escolas precisam elaborar uma proposta curricular inovadora que amplie o tempo do estudante na escola e atividades integradoras que articulem trabalho, da ciência, da cultura e da tecnologia, contemplando as diversas áreas do conhecimento definidas nas Diretrizes Curriculares Nacionais. No documento orientador do MEC divulgado em 2009, as SEE deveriam garantir a ampliação da carga horaria das escolas e oferecer garantias de lotação dos professores numa única unidade escolar para que elas pudessem participar do Proemi. As escolas que aderirem recebem apoio técnico e financeiro do MEC. Em 2013, foi divulgada uma tabela de repasse de recursos do MEC para escolas com uma jornada escolar diária de cinco horas e para as escolas do período noturno (Resolução/CD/FNDE n. 31, de 22 de julho de 2013). 
10. Disponível em:<http://www.camara.gov.br/proposicoesWeb/fichadetramitacao?idProposicao= 602570>

11. Decreto n. 5.154/04.

12. Antigos Centros Federais de Educação Tecnológica (Cefets).

13. Bowles e Gintis, na década de 1970, fizeram um aporte importante para a análise dos processos de reprodução social ao demonstrar laços de correspondência entre o desenvolvimento do sistema escolar norte-americano e o sistema produtivo capitalista, não tanto pelo conteúdo que se ensina, mas principalmente através da aprendizagem de atitudes necessárias para se qualificar como "um bom trabalhador" (BOWLES; GINTIS, 1981).

14. É uma modalidade que recebe diferentes nomes, por exemplo, em Pernambuco, são as escolas de referência; em São Paulo, são escolas de tempo integral.

15. Parte das escolas compõe o ensino médio integrado à educação profissional.

16. O empresário Marcos Magalhães mobilizou um conjunto de outros empresários para restaurar o Ginásio Pernambucano, escola onde ele e figuras públicas do estado tinham estudado, e posteriormente, como desdobramento dessa iniciativa, implantou nessa escola, com anuência da SEE, um projeto de gestão compartilhada baseado na experiência realizada na empresa Odebrecht. A proposta testada foi implantada posteriormente num conjunto de escolas públicas de ensino médio em Pernambuco.

17. Tem como base o modelo de gestão desenvolvido pelo grupo Odebrecht, conhecido como TEO (Tecnologia Empresarial Odebrecht)

18. Com algumas diferenças por estados.

19. Relatório Final da Comissão de Reformulação do Ensino Médio na Câmara de Deputados, dezembro de 2013. Presidente: Deputado Reginaldo Lopes (PT-MG); Relator: Deputado Wilson Filho (PMDB-PB).

20. Disponível em: $<\mathrm{http}: / /$ www.camara.gov.br/proposicoesWeb/fichadetramitacao?idProposicao= 602570>. O referido Projeto de Lei, por tratar de matéria de competência de mais de três comissões de mérito, será analisado por uma Comissão Especial que se encontra em fase de constituição. De ser aprovado o Projeto de Lei, o ensino médio passará a ter uma base comum nos dois primeiros anos e uma parte diversificada no terceiro ano, com diferentes opções formativas: formação profissional, ciências da natureza ou ciências humanas.

21. Vimos, quando nos referimos ao ensino médio noturno, a superposição da proposta da Comissão de Reformulação do Ensino Médio à EJA.

22. Lei do Voluntariado, fevereiro de 1998. Organização Social (1998) e Organização Social de Interesse Público (Oscip) (1999).

23. Erika Martins (2013) realizou um estudo sobre a atuação do Movimento Todos Pela Educação que mostra, através de uma pesquisa empírica, o espaço do empresariado no âmbito da formulação de políticas e da mobilização social.

24. Armando Boito Jr. retoma o conceito de burguesia interna, cunhado por Poulantzas na década de 1970, que, segundo o autor, não se encontrava em vias de desaparecimento com a nova onda de internacionalização da economia capitalista.

\section{Referências}

AGÊNCIA BRASIL. Quase 90\% dos alunos que vão concluir ensino médio se inscreveram no Enem. Jornal do Brasil, 11 jun. 2013. Disponível em: <http://www.jb.com. br/pais/noticias/2013/05/28/quase-90-dos-alunos-que-vao-concluir-ensino-mediose-inscreveram-no-enem/>. Acesso em: 12 jul. 2013. 
BARROSO, J.; NATÉRCIO, A. (Org.). Políticas educativas: mobilização de conhecimento e modos de regulação. Lisboa: Fundação Manuel Leão, 2011.

BOITO JUNIOR, A. Governos Lula: a nova burguesia nacional no poder. In: BOITO JUNIOR, A.; GALVÃO, A. (Org.). Política e classes sociais no Brasil dos anos 2000. São Paulo: Alameda, 2012. p. 67-103.

BOITO JUNIOR, A.; GALVÃO, A. (Org.). Política e classes sociais no Brasil dos anos 2000. São Paulo: Alameda, 2012.

BOWLES, S.; GINTIS, H. La instrucción escola en la América capitalista. México, DF: Siglo XXI, 1981.

BRASIL. Presidência da República. Emenda Constitucional n. 59, de 11 de novembro de 2009. Acrescenta $\S 3^{0}$ ao art. 76 do Ato das Disposições Constitucionais Transitórias para reduzir, anualmente, a partir do exercício de 2009... Diário Oficial da União, Brasília, DF, 12 nov. 2009. Disponível em: <http://www.planalto.gov.br/ ccivil_03/constituicao/Emendas/Emc/emc59.htm>. Acesso em: 12 mar. 2011.

DELVAUX, B. Qual é o papel do conhecimento na acção pública? Educação \& Sociedade, Campinas, v. 30, n. 109, p. 959-985, set/dez, 2009.

DIAS, M.C.N.; GUEDES, P.M. Modelo de escola charter: a experiência de Pernambuco. São Paulo: Instituto Fernand Braudel; Fundação Itaú Social, 2010.

FERNANDES, F. A revolução burguesa no Brasil: ensaio de interpretação sociológica. Rio de Janeiro: Zahar, 1981.

HARVEY, D. Condição pós-moderna. São Paulo: Loyola, 2012.

JACINTO, C.; TERIGI, F. ¿Qué hacer ante las desigualdades en la educación secundaria? Buenos Aires: Santillana; Instituto Internacional de Planeamiento de la Educación-Unesco, 2007.

LIMA, I.A.A.P. Tear. Tecnologia Empresarial Aplicada à Educação: gestão e resultados. Olinda: Livro Rápido, 2011.

LODI, L.; KRAWCZYK, N. O ensino médio e a educação profissional técnica de nível médio: desafios curriculares. Trabalho apresentado no Colóquio Luso-Brasileiro sobre Questões Curriculares, Florianópolis, 4 set. 2008.

KRAWCZYK, N. O ensino médio no Brasil. São Paulo: Ação Educativa, 2009.

KRAWCZYK, N. Conhecimento crítico e política educacional: um diálogo difícil, mas necessário. In: KRAWCZYK, N. (Org.). Sociologia do ensino médio: crítica ao economicismo na política educacional. São Paulo: Cortez, 2014. 
MAGALHÃES, M. A juventude brasileira ganha uma nova escola de ensino médio: Pernambuco cria, experimenta e aprova. São Paulo: Albatroz; Loqui, 2008.

MARTINS, E.M. "Movimento Todos pela Educação": um projeto de nação para a educação brasileira. 2013. Dissertação (Mestrado em Educação) - Faculdade de Educação, Universidade Estadual de Campinas, Campinas.

SÃO PAULO (Estado). Secretaria de Educação. Ensino integral: modelo de Gestão Educacional de São Paulo. São Paulo: SEE-SP, 2011. (Documento).

SOUZA, D.M. Palestra no Seminário de Reformulação do Ensino Médio representando o CONSED, out. 2013. Brasília, DF: Senado Nacional, 2013

SPOSITO, M.P. Algumas reflexões e muitas indagações sobre as relações entre juventude e escola no Brasil. In: ABRAMO, H.W.; BRANCO, P.P.M. (Org.). Retratos da juventude brasileira: análises de uma pesquisa nacional. São Paulo: Fundação Perseu Abramo, 2005.

TIRAMONTI, G. (Dir.). Variaciones sobre la forma escolar: limites e possibilidades de la escuela media. Buenos Aires: Flacso; Homo Sapiens, 2011.

ZIEGLER, S. Docentes de la elite, elites docentes: la configuración de la labor pedagógica y de una comunidad de profesores para la formación de los sectores privilegiados. 2012. Tese (Doutorado em Ciências Sociais) - Facultad Latinoamericana de Ciencias Sociales, Buenos Aires.

Recebido em 2 de fevereiro de 2014.

Aprovado em 7 de março de 2014. 